\section{Deregulierung durch die EU}

Bestehende Regulierungen bezüglich der Anforderungen an Zugangsqualifikationen zum zahnärztlichen Beruf bilden für den FVDZ die Grundlage einer leistungsfähigen Zahnheilkunde in Deutschland.

Was entgegnet Ihre Partei den gegenwärtigen Entwicklungen auf europäischer Ebene, unter Nichtbeachtung des Subsidiaritätsprinzips Einfluss auf die nationale Gesetzgebung zu nehmen, beispielsweise aktuell mit dem Dienstleistungspaket?
Zu einer starken Gemeinschaft gehört es, das Subsidiaritätsprinzip in der EU zu wahren. Mit dem Kommissionsvorschlag für ein „Dienstleistungspaket" wird dieses Prinzip deutlich verletzt, und zwar nicht allein im Bereich der Anforderungen für die zahnärztliche Berufsausübung. Wir Freie Demokraten lehnen insofern den Vorschlag in der jetzigen Form ab.

\title{
Ein Kommentar zur Verstaatlichung des Gesundheitssystems
}

\section{Noch mehr Staat, bitte?}

Der Umgang des Staates mit den Heilberuflern ist unterirdisch. Der Vertrauenskultur von gestern steht heute eine ausgeprägte Misstrauenskultur gegenüber.

\section{Worum geht es im heutigen Gesundheitssystem?}

Es geht nicht darum, gut funktionierende Strukturen noch zu verbessern. Es geht nicht um Vertrauen in einen gesellschaftlich relevanten und anerkannten Berufsstand. Es geht um Misstrauen, es geht um die Schalthebel, es geht schlicht um die Macht über die Gesundheitsversorgung der Menschen. Und weil kaum noch ein Bürger das System mit seinen Verstrickungen, Verästelungen und Quersubventionierungen noch durchdenken kann, kommen die Partei-Oligarchen und suggerieren dem Bürger: Wir machen das schon für euch!

Sie lassen den Bürger glauben, sie könnten es tatsächlich besser. Aber das kann der Staat eben nicht. Der Staat ist ökonomisch nachweislich wenig erfolgreich - auch weil da ja niemand für den verzapften Mist haften muss. Hauptsache die Anästhesie ist billiger als die Currywurst!

Der Staat kann vor allem eines nicht: eine Rolle spielen, die das Vertrauen zwischen Arzt und Patient stärkt. Einmischung des Staates in diese Vertrauensbeziehung bedeutet zwangsläufig einen Verlust an Freiheit. Aber über die Freiheit diskutieren bekanntlich nur diejenigen, die ihre Freiheit verloren haben.

\section{Heute ist fast alles vorgegeben}

Früher konnten die Akteure im Gesundheitssystem noch das eine oder andere aushandeln, es wurden auch mal sinnvolle Einzelentscheidungen getroffen. Heute ist fast alles vorgegeben. Heute darf die Akzeptanz staatlicher Vorgaben und staatlichen Handelns kaum noch durch Zwischenfragen gestört oder getrübt werden. Die Obrigkeit verlangt, dass alle Akteure sich auf die staatliche Agenda einlassen und die dort verfügten Veränderungen bis in kleinste Detail hinnehmen. So redet das neue Jakobinertum in unserem Land! „Alle müssen!“ Und sie sagen: Wenn sich ein Berufsstand weigert, dann werden wir ihn nicht für Zivilcourage auszeichnen, sondern in die Daumenschrauben zwingen. Alles angeblich zum Wohle der Gesellschaft? Nein, alles ist zum Wohle der Oligarchie! Ich nenne das die Forderung nach Unterwerfung.

\section{Und wir Zahnärzte?}

Oft sind wir in Sachen eigener Interessenvertretung faul und feige geblieben, dabei werden wir

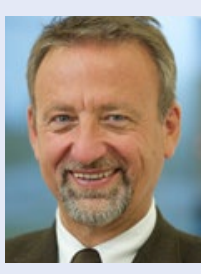

Dr. K. Ulrich Rubehn in die Enge getrieben von denen, die sich so viel nehmen an Zeit für den Kampf gegen unsere Freiberuflichkeit.

Wollen wir uns nur rückhaltlos wohlfühlen? Und beruhigt sein durch moralisch einwandfreies Handeln? Programmiert durch die allabendlichen Moralin-geladenen Talkshows? Lassen wir uns nicht verheddern in der Endlosschleife eines staatlich verordneten Tuns. Oder sogar eines verordneten entsprechenden Denkens! Die uns vertretenden Körperschaften könnten sagen: Jetzt ist mal Schluss! Wir im unabhängigen Freien Verband können sogar danach handeln! Wozu verfolgt der Staat die scheibchenweise Verstaatlichung unseres Gesundheitswesens? Wozu die Realitätsumwandlung eines Systems, das doch jeden Vergleich mit den umliegenden Ländern locker bestehen kann? Man kann die Heilberufe dazu bringen, in einer Kühlkammer zu schwitzen. Man kann sie auch dazu bringen, in einer Sauna zu frieren. Vorausgesetzt man erklärt das alles zu Bewährungsproben! Wollen wir ein solches Experiment mit unsicherem Ausgang? Wir sollten es nicht wollen.

\section{Gibt es für uns eine Pflicht zum Intervenieren?}

Muss man Fluten, Lawinen, Vandalen oder falsche Politik bekämpfen? Man muss nicht. Aber man kann!

Dr. K. Ulrich Rubehn

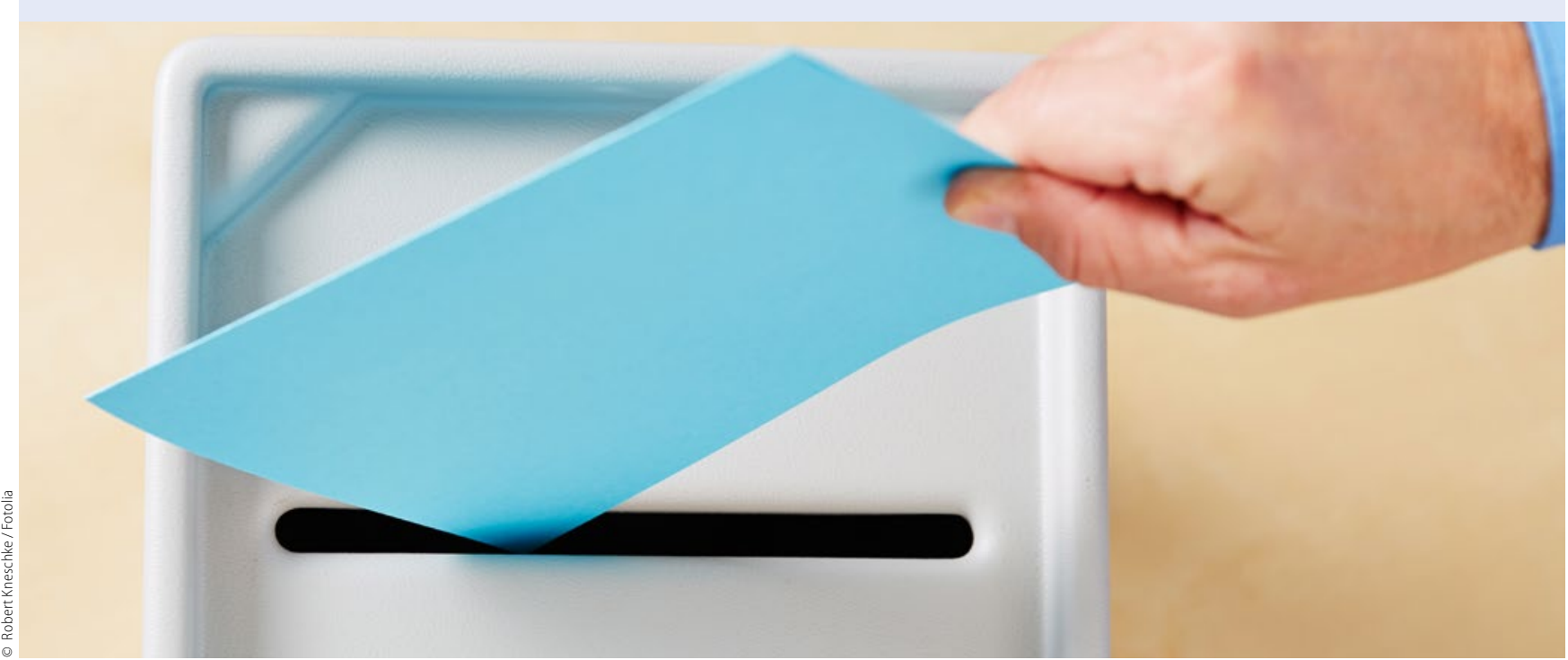

